\title{
Population neuroscience: challenges and opportunities for psychiatric research in low- and middle-income countries
}

\author{
Alessandra Cirillo, ${ }^{1,2}$ iD Elton Diniz, ${ }^{3,4}$ Ary Gadelha, ${ }^{3,4}$ Elson Asevedo, ${ }^{1,3}$ iD Luiza K. Axelrud, ${ }^{5,6,7}$ \\ Eurípedes C. Miguel, ${ }^{5,8}$ Luis Augusto Rohde, ${ }^{5,7,9}$ Rodrigo A. Bressan, ${ }^{3,4,5}$ Pedro Pan, ${ }^{3,4,5}$ \\ Jair de J. Mari ${ }^{3,4,5}$ iD \\ ${ }^{1}$ Global Mental Health Program, Columbia University, New York, NY, USA. ${ }^{2}$ Columbia University Mailman School of Public Health, New York, \\ NY, USA. ${ }^{3}$ Departamento de Psiquiatria, Universidade Federal de São Paulo (UNIFESP), São Paulo, SP, Brazil. ${ }^{4}$ Laboratório Interdisciplinar \\ de Neurociências Clínicas (LiNC), Departamento de Psiquiatria, UNIFESP, São Paulo, SP, Brazil. ${ }^{5}$ Instituto Nacional de Psiquiatria do \\ Desenvolvimento para Crianças e Adolescentes (INPD), Departamento de Psiquiatria, Universidade de São Paulo (USP), São Paulo, SP, \\ Brazil. ${ }^{6}$ Seção de Afetos Negativos e Processos Sociais, Departamento de Psiquiatria e Medicina Legal, Universidade Federal do Rio Grande \\ do Sul (UFRGS), Hospital das Clínicas de Porto Alegre (HCPA), Porto Alegre, RS, Brazil. ${ }^{7}$ Programa de Pós-Graduação em Psiquiatria e \\ Ciências do Comportamento, Departamento de Psiquiatria, UFRGS, Porto Alegre, RS, Brazil. ${ }^{8}$ Departamento de Psiquiatria, Faculdade de \\ Medicina, USP, São Paulo, SP, Brazil. ${ }^{9}$ Serviço de Psiquiatria da Infância e Adolescência, HCPA, Departamento de Psiquiatria, UFRGS, Porto \\ Alegre, RS, Brazil.
}

\begin{abstract}
Objective: Population neuroscience is an emerging field that combines epidemiology and neuroscience to study how genes and the environment shape typical and atypical brain functioning. The objective of this study was to review key studies on population neuroscience from low- and middle-income countries (LMICs) and to identify potential gaps vis-à-vis studies conducted in highincome countries.

Methods: We conducted a systematic review to search for longitudinal cohort studies investigating the development of psychiatric disorders in children and adolescents in LMICs. We performed an electronic search in the EMBASE and MEDLINE databases from inception to July 5th, 2019.

Results: We found six cohorts from four countries that met our search criteria: three cohorts from Brazil, one from China, one from South Africa, and one from Mauritius. Relevant examples of findings from these studies are reported.

Conclusion: Our results demonstrate the impact of the valuable science output these cohort designs promote, allowing LMICs to have a share in frontline global psychiatry research. National and international funding agencies should invest in LMIC population neuroscience in order to promote replication and generalization of research from high-income countries.
\end{abstract}

Keywords: Neuroscience; epidemiology; population neuroscience; low- and middle-income countries; review

\section{Introduction}

Psychiatry is a hybrid discipline encompassing the study of a variety of behavioral abnormalities, conceptualized both clinically and historically, that ultimately result from qualitative and/or quantitative dysfunctions of the brain. It is strongly pragmatic, having to serve the needs of clinicians, administrators, and funders, but is progressively becoming more scientifically oriented. Two of the major scientific fields that inform psychiatry are epidemiology and neuroscience, which have developed completely separately and, until recently, rarely interacted with each other.

Correspondence: Jair de Jesus Mari, Departamento de Psiquiatria, Escola Paulista de Medicina, Universidade Federal de São Paulo, Rua Major Maragliano, 241, Vila Mariana, CEP 04017-030, São Paulo, SP, Brazil.

E-mail: jamari17@gmail.com

Submitted Oct 23 2019, accepted Dec 01 2019, Epub Apr 032020.
Psychiatric epidemiology has been essential to the development of scientific psychiatry. For example, it has identified the prevalence, recurrence, and chronicity of psychiatric disorders, ${ }^{1}$ as well as their developmental nature. ${ }^{2,3}$ It has revealed problems with our diagnostic reliability (low agreement between independent opinions of investigators) ${ }^{4}$ and raised questions about the validity of psychiatric disorders (low predictive information with respect to class membership). In its application to therapeutics (e.g., randomized clinical trials), it has revealed the non-specificity of our treatment options. ${ }^{5}$ In its interaction with genetics, it has exposed the fragilities of our diagnostic boundaries ${ }^{6}$ and clarified the complexities of causality of psychiatric traits. ${ }^{7}$

How to cite this article: Cirillo A, Diniz E, Gadelha A, Asevedo E, Axelrud LK, Miguel EC, et al. Population neuroscience: challenges and opportunities for psychiatric research in low- and middle-income countries. Braz J Psychiatry. 2020;42:442-448. http://dx.doi.org/ 10.1590/1516-4446-2019-0761 
Population neuroscience is a new subfield that aims to bring together epidemiology and neuroscience to increase the external validity, reliability, and generalizability of neuroscience findings. ${ }^{8,9}$ The overwhelming amount of complexity involved in interacting risk factors (genome and environment) and resulting phenotypes at several levels of biological coherence (phenome) is the main rationale for this integration. Scientific integration can help develop methods to deal with complex phenomena, not only as a result of the additive effects of their components, but also to study the characteristics of the phenomena as a whole. ${ }^{10}$ According to Paus, ${ }^{8,9}$ who coined the term "population neuroscience," the main goals of this new discipline are twofold: a) to advance our understanding of interindividual variability in the human brain and its behavioral products; and b) to use information from genes and environments to individualize prediction of risk in order to develop personalized preventive strategies tailored to the at-risk individual. ${ }^{8,9}$

Here, we review the literature on longitudinal, population-based cohort studies from low- and middle-income countries (LMICs) that utilize genetics or neuroimaging to explore the interindividual brain variability of psychiatric disorders during neurodevelopment and the predictive ability of certain biological and environmental risk factors. This is essential because risk factors are populational, while disease is an individual experience.

\section{Methods}

The systematic review followed PRISMA (Preferred Reporting Items for Systematic Reviews and Meta-Analyses) guidelines.

\section{Search strategy}

We performed an electronic search in the EMBASE and MEDLINE databases, on July 5th, 2019, using the following keywords (MeSH and text words) to describe 1) study population: children, child, childhood, adolescent, adolescence, teenager, youth; 2) study design: cohort studies; 3) outcomes of interest: psychopathology, psychiatric disorder, mental disorder, psychiatry; 4) developing country, developing world, low and middle income country, LMIC, low income country, middle income country, and the individual country names defined in 2015 by the World Bank lending classification as low or middle income using Gross National Income (GNI) per capita of less than $\$ 12,735$. We also handsearched the reference lists of the selected papers and of relevant reviews for additional studies.

\section{Inclusion and exclusion criteria}

Only original, peer-reviewed articles in English, without restrictions on the date of publication, were included. An article was eligible if it referred to a longitudinal, population-based study design, regardless of recruitment method; was set in a LMIC; included participants from birth to 17 years old; assessed any standardized psychiatric diagnosis on individuals up to 17 years old; and utilized measurements in genetics, neuroimaging, psychopathology, or cognition. Articles with a cross-sectional design were included if they utilized data from cohort studies that satisfied the inclusion criteria. Studies conducted with samples not representative of the population were excluded, as well as those that recruited subjects with a previous psychiatric diagnosis (e.g., schizophrenia).

Two investigators (AC and ED) screened all studies by title and abstract independently. The studies included for the full-text review phase were also evaluated independently by the two authors. After each phase was completed, blinding was removed and any conflicts were resolved by consensus, consulting with another investigator (JM) when necessary.

\section{Data extraction}

Two authors ( $A C$ and $E D$ ) extracted the following information independently from each included study: metadata (cohort identification, year of beginning, country of origin), characteristics of the participants (number, age), study design, length of the cohort, assessment instruments, and main findings. The main findings were extracted selectively so as to provide some examples of the potential outcomes obtained from cohort studies conducted in LMICs.

\section{Results}

Figure 1 provides a PRISMA flow diagram of study screening and inclusion.

Our search resulted in six cohort studies from four countries (Brazil, China, South Africa, and Mauritius), five of which are birth cohorts. Table 1 describes the design, including sample characteristics, as well as examples of findings from each study. The High-Risk Cohort Study for the Development of Childhood Psychiatric Disorders (HRC), an ongoing longitudinal cohort study conducted in Brazil, is highlighted here due to its innovative methodology among LMICs that includes psychopathology, cognitive assessments, genetics, and neuroimaging. Our search elicited 12 studies resulting from the HRC, including the following topics and methodologies: functional connectivity and depression, ${ }^{11}$ the role of inflammation in mental health problems in children, ${ }^{12}$ cortical structure in children and adolescents with psychiatric disorders, ${ }^{13}$ spontaneous brain activity involved in obsessive compulsive symptoms, ${ }^{14}$ self-harm, ${ }^{15}$ perinatal complications and mental health problems in children and adolescents, ${ }^{16}$ dynamic functional connectivity and psychopathology, ${ }^{17}$ attention bias to threat, ${ }^{18}$ the association between obsessive compulsive symptoms and psychopathology/behavior problems, ${ }^{19}$ the genetics of attention-deficit/hyperactivity disorder (ADHD), ${ }^{20}$ the utilization of mental health services by children, ${ }^{21}$ and the economic impact of childhood mental disorders. $^{22}$

The 1993 and 2004 Pelotas Birth Cohorts have also been conducted in Brazil and produced significant results in child and adolescent mental health. Eight studies from the 1993 Pelotas Birth Cohort were included from our 


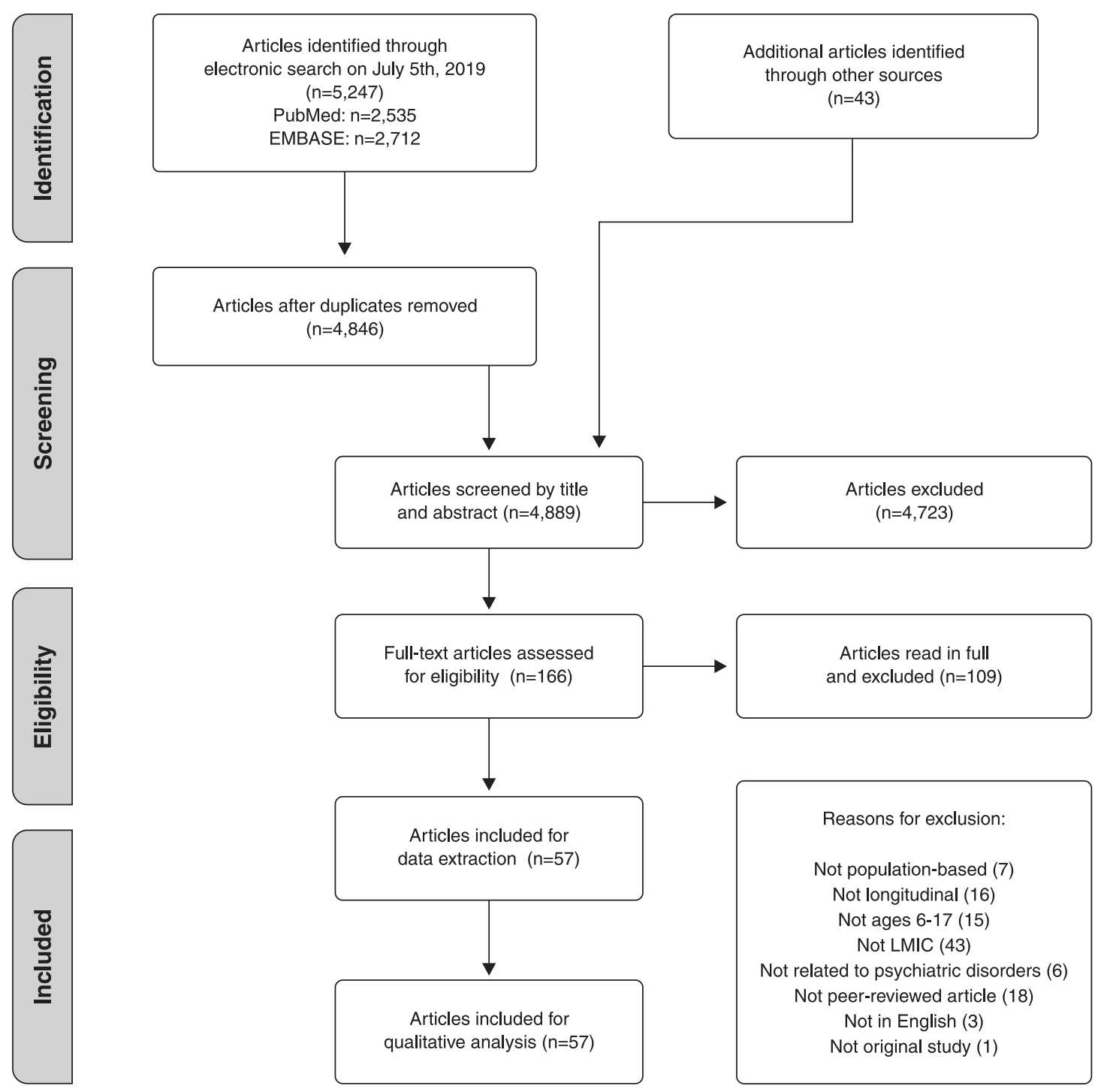

Figure 1 PRISMA flow diagram. LMIC = low- and middle-income country.

search, including the following topics: genes associated with ADHD symptoms in adolescents, ${ }^{39,40}$ geneenvironment interaction on externalizing problems in adolescents, ${ }^{41}$ the effects of socioeconomic changes on psychopathology in adolescents, ${ }^{25}$ the prevalence of psychopathology in 11 -year-olds, ${ }^{42}$ the continuity of behavioral and emotional problems from childhood into pre-adolescence, ${ }^{43}$ adverse childhood experiences and alcohol, tobacco, and drug use, ${ }^{44}$ and determinants of attention and hyperactivity problems in adolescents. ${ }^{26}$ Thirteen studies from the 2004 Pelotas Birth Cohort were included from our search, including the following topics: the effects of early hospitalization on psychiatric disorders in children and pre-adolescents, ${ }^{45}$ the prevalence of psychiatric disorders in children/pre-adolescents, ${ }^{28,29}$ risk factors for disruptive mood dysregulation disorder, ${ }^{46}$ ADHD associations, ${ }^{47-49}$ maternal mood disorders/symptoms and child psychopathology, ${ }^{50,51}$ intrauterine exposure and emotional/hyperactivity problems, ${ }^{30}$ breastfeeding and mental health in children, ${ }^{52}$ gestational age at birth and behavioral problems, ${ }^{53}$ and bed-sharing and psychiatric disorders in children. ${ }^{54}$

The Hong Kong Children of 1997 is a birth cohort study conducted in China that covers a wide range of health issues in children and adolescents, including mental health. Our search resulted in seven studies from this cohort, which comprised the following topics: how behavior problems and self-esteem are related to depression in adolescents, ${ }^{32}$ mode of delivery and psychological problems in children and adolescents, ${ }^{55}$ the onset of puberty and depression in adolescents, ${ }^{33}$ second-hand smoke exposure and mental health in adolescents, ${ }^{56}$ child care and mental health in adolescents, ${ }^{57}$ life-course adiposity and depression in adolescents, ${ }^{58}$ and breastfeeding and mental health in adolescents. ${ }^{59}$

The Birth to Twenty cohort is a birth cohort conducted in South Africa that also covers a wide range of health issues in children and adolescents, including mental health. Two studies from this cohort were included: one on 
Table 1 Study design and examples findings from each cohort

\begin{tabular}{lll}
\hline Cohort & Country & Study design \\
\hline $\begin{array}{l}\text { High-Risk Cohort Study for } \\
\text { the Development of }\end{array}$ & Brazil & From a screening phase of 9,937 subjects (6 to \\
Childhood Psychiatric & & 14 years of age), a total of 2,512 (958 randomly \\
Disorders & selected and 1,554 at high risk for mental \\
& disorders defined by symptoms and family \\
& history) were selected for further detailed \\
& evaluation (parental and child interviews and \\
& cognitive testing). Saliva samples were collected \\
& from trios of index subjects. A subsample of \\
& inclunderwent multimodal MRI techniques \\
& including T1-weighted structural, diffusion \\
& tension imaging, and resting-state functional \\
& connectivity, as well as blood sampling for \\
& biomarker evaluation. ${ }^{10}$
\end{tabular}

1993 Pelotas Birth Cohort Brazil A total of 5,249 subjects were enrolled at birth and subsamples were followed up at 1,3 , and 6 months and $1,4,6,9$, and $12-13$ years of age. All subjects were followed up at 11 and 15 years of age. Data was collected from questionnaires and interviews, and DNA was extracted from saliva. 23,24

2004 Pelotas Birth Cohort Brazil A total of 4,231 subjects were enrolled at birth and all were followed up at $3,12,24$, and 48 months and 6-7 and 11 years of age. Data was collected from questionnaires and interviews. ${ }^{27}$

\begin{tabular}{|c|c|c|}
\hline $\begin{array}{l}\text { Hong Kong Children of } \\
1997\end{array}$ & China & $\begin{array}{l}\text { A total of } 8,327 \text { subjects were enrolled at } \\
\text { birth and followed up through age } 13 \text {. Data } \\
\text { was collected from self-report questionnaires } \\
\text { and clinical measurements. }\end{array}$ \\
\hline
\end{tabular}

Birth to Twenty South A total of 3,273 subjects were enrolled at birth Africa and followed up at 6 months and $1,2,3-4,5$, $7-8,9-10,11-12,13,14$, and 15 years of age. Data was collected from questionnaires, interview, and clinical measurements. ${ }^{34}$

Mauritius Child Health Study
Examples of findings

- Atypical ventral striatum functional connectivity predicted future risk for depressive disorder. ${ }^{11}$ - Systemic inflammation may be involved in the pathway linking familial risk and mental health problems in children. ${ }^{12}$

- Poverty was associated with more conduct problems and, to a lesser extent, emotional problems in adolescents. ${ }^{25}$

- Attention and hyperactivity problems at age 11 were associated with male gender, low family income, smoking during pregnancy, maternal psychiatric disorder, and behavioral/emotional problems at age $4 .^{26}$

- The prevalence of psychiatric disorders was higher in boys than girls at ages 6 and 11. ${ }^{28,29}$ - Intrauterine exposure to acetaminophen was associated with emotional and hyperactivity/ inattention problems in boys at age 6 and less so at age $11 .{ }^{30}$

- Childhood behavioral problems and low self-esteem predicted adolescent depressive symptoms. ${ }^{32}$

- Early onset of breast development was associated with higher risk of depression. ${ }^{33}$

- Maternal postnatal depression was associated with adverse psychological outcomes in children at age 10.35

- Malnutrition at age 3 predicted externalizing
behavior problems at ages 8,11 , and $17 .^{37}$
- Birth complications are associated with
increased externalizing behavior at age $11 .{ }^{38}$

$\mathrm{MRI}=$ magnetic resonance imaging.

maternal depression and psychological outcomes at age $10,{ }^{35}$ and one on low birth weight and emotional and behavioral outcomes at age $12 .{ }^{60}$

Finally, we found the Mauritius Child Health Study, a cohort study assessing child and adolescent health outcomes from age 3 . Seven studies from this cohort were included: two on aggression, ${ }^{61,62}$ one on antisocial behavior, ${ }^{63}$ two on externalizing behavior, ${ }^{37,38}$ one on conduct disorder, ${ }^{64}$ and one on schizotypal personality. ${ }^{65}$

\section{Discussion}

Our search yielded three cohorts from Brazil, one from China, one from South Africa, and one from Mauritius. Each study produced significant findings on the development of psychiatric disorders in children and adolescents that have contributed to the fields of psychiatry, neuroscience, and psychiatric epidemiology.

The following two papers produced from the HRC demonstrate the high-quality results that are achieved from utilizing this longitudinal epidemiological study design and the potential impact of these results:

Pan et al. ${ }^{11}$ was the first study to link aberrant connectivity in the ventral striatum as a predictor of MDD using HRC data. Depression incidence rises from late childhood to early adolescence. Interestingly, this is also an important period for maturation of the brain's rewardprocessing systems. Using this large community-based sample, the authors used a discovery and replication procedure, dividing the cohort by study site, to establish a functional magnetic resonance imaging (fMRI) restingstate brain network consisting of reward-related brain 
regions. Baseline functional connectivity within this resting-state reward network was then associated with clinical depression after 3 years of follow-up. They analyzed fMRI from 637 subjects aged 6-12 years at baseline. The results showed that left striatal node strength, a measure of how a specific node is connected within the entire network, predicted depressive disorder onset at follow-up, even when subjects depressed at baseline were excluded. Moreover, this finding was specific for depression, since higher striatal node strength did not predict other common adolescent psychopathologies (such as anxiety, attentiondeficit/hyperactivity disorder, or substance use). These results are important because they show, for the first time, that aberrant connectivity within the reward network already occurs before the clinical diagnosis of depression. It supports the hypothesis of an impaired reward system as a fundamental etiological aspect of adolescent depression. ${ }^{11}$

Previous studies showed associations between polygenic risk score for Alzheimer's disease and both memory decline and lower hippocampal volume in adults. Nevertheless, studies investigating this issue in youth were lacking. The second HRC study we report herein aimed to investigate the impacts of a polygenic risk score for Alzheimer's disease on cognition and hippocampal volume in two samples of children from Brazil $(\mathrm{N}=364$ and $\mathrm{N}=352$ ) and in an additional replication sample from Canada $(\mathrm{N}=1,029)$. Subjects underwent genotyping, MRI, and cognitive tests. Genetic risk for Alzheimer's disease was calculated based on previous genome-wide association studies (GWAS). The authors found that, for the Brazilian samples, the genetic risk for Alzheimer's disease was associated with lower performance in both immediate and delayed recall. They also found an associations between polygenic risk score for Alzheimer's disease and lower hippocampal volume, but only for individuals with high genetic risk. Finally, they found that these association were not driven solely by the apolipoprotein $\mathrm{E} \varepsilon 4$ allele or by any other single nucleotide polymorphism separately, but by the aggregated genetic risk. Associations fell short of significance for the Canadian sample. These findings suggest that even neurodegenerative disorders such as Alzheimer's disease may have neurodevelopmental origins, providing further insight into Alzheimer's disease pathogenesis. This might also help advance the identification of individuals at higher risk and the development of strategies for the disease's prevention. ${ }^{66}$

Both of these studies show how techniques such as neuroimaging and genetics can be used to identify individuals at high risk for psychiatric disorders before a formal diagnosis would typically be made. This can be extremely useful not only for understanding how and why these disorders develop, but also to allow those at high risk to receive treatment before the disorder progresses.

There are several limitations to our study. First, it is not a comprehensive review of all cohort studies. As discussed in the methodology, we restricted our results to longitudinal cohort studies conducted in LMICs that were population-based, thus excluding studies involving specific populations.

There are many challenges in conducting longitudinal epidemiological studies involving child and adolescent psychiatry in LMICs. Some of these challenges include cost, difficulties in recruitment, loss of subjects to followup (largely due to lack of accessible forms of communication and incentive to participate), lack of sufficient trained personnel, issues obtaining reliable, valid data, and lack of standardized procedures for data collection and analysis. ${ }^{67}$ Study burden is another significant barrier to participation in these types of studies, especially in LMICs where subjects may not have the means to return to the study site for follow-up; education level tends to be lower, making it more difficult and time-consuming to complete interviews; and privacy is often an issue, as subjects could face severe consequences if sensitive information is leaked. Furthermore, psychiatric disorders are often overlooked in LMICs while infectious diseases and physical chronic disorders are prioritized.

These results have significant implications for future research and practice. The scarcity of research in population neuroscience in LMICs presents an exciting opportunity for further psychiatric research utilizing a similar study design to those previously described. The ability to identify at-risk individuals can allow mental health professionals to prevent the progression of psychiatric disorders. The findings of the studies discussed herein demonstrate that there is much more research to be done at the intersection of psychiatry and neuroscience that will help to advance both fields. In addition, more effective treatments and preventive strategies can be gained by identifying biomarkers that indicate and predict key pathogenic mechanisms underlying a given disease or an individual's response to a specific treatment. ${ }^{8,9}$ In reality, it is likely that several biomarkers should be evaluated to predict the risk of a given individual with high accuracy. The concept of risk/resilience profiling (the balance between risk and resilience factors) may serve as an alternative to prevention. Knowledge about the factors and mechanisms associated with diversity in our brain phenotypes may ultimately allow us to predict risk and prevent and mitigate suffering involved by advancing so-called personalized preventive medicine ${ }^{8,9}$ or stratified medicine. ${ }^{68}$ Such types of strategies are expected to be able to tremendously increase effective interventions and, consequently, improve care for psychiatric patients.

In conclusion, our results demonstrate that it is possible to conduct longitudinal cohort studies in LMICs despite challenges, and that such studies produce valuable results that help to inform the fields of psychiatry utilizing a population neuroscience strategy. This is important because these results can inspire new, innovative research and improve clinical practice in psychiatry. We encourage other LMICs to adopt this strategy and conduct similar studies in order to produce similarly valuable results and further advance these fields.

\section{Acknowledgements}

This study was supported by Instituto Nacional de Psiquiatria do Desenvolvimento para Crianças e Adolescentes (INPD) (grants: Conselho Nacional de Desenvolvimento Científico e Tecnológico [CNPq] 465550/2014-2 and Fundação de Amparo à Pesquisa do Estado de São Paulo 
[FAPESP] 2014/50917-0). AC is an MSc student (Public Health) at Columbia University Mailman School of Public Health and served as a research assistant at Universidade Federal de São Paulo (UNIFESP) through the Global Mental Health Program. RAB has received research grants from government funding agencies (Coordenação de Aperfeiçoamento de Pessoal de Nível Superior [CAPES], CNPq, and FAPESP). PP reports grants from FAPESP (2014/50917-0) and CNPq (465550/2014-2). JJM is a CNPq senior researcher.

We are grateful to Dr. Giovanni Salum for his relevant contributions in the planning of this paper.

\section{Disclosure}

AG has received financial support from Janssen and Daiichi-Sankyo as a member of advisory boards, and from Aché, Cristália, and Torrent as a speaker. LAR has received grant or research support from, served as a consultant to, or served on the speakers' bureaus of Eli Lilly, Janssen, Medice, Novartis, and Shire; has received authorship royalties from Oxford Press and Artmed and travel grants from Shire to take part in the 2018 APA annual meeting, and from Novartis to take part of the 2017 World Federation of ADHD annual meeting; and the ADHD and Juvenile Bipolar Disorder Outpatient Programs chaired by him have received unrestricted educational and research support from the following pharmaceutical companies: Eli Lilly, Janssen, and Novartis. RAB has received research grants from Janssen Cilag, Novartis, and Roche; has been a forum consultant for Janssen, Novartis, and Roche; and has participated in speakers' bureaus for Aché, Bayer, Pfizer, Janssen, Lundbeck, and Novartis. The other authors report no conflicts of interest.

\section{References}

1 Murray CJ, Vos T, Lozano R, Naghavi M, Flaxman AD, Michaud C, et al. Disability-adjusted life years (DALYs) for 291 diseases and injuries in 21 regions, 1990-2010: a systematic analysis for the Global Burden of Disease Study 2010. Lancet. 2012;380:2197-223.

2 Kessler RC, Angermeyer M, Anthony JC, DE Graaf R, Demyttenaere $\mathrm{K}$, Gasquet I, et al. Lifetime prevalence and age-of-onset distributions of mental disorders in the World Health Organization's World Mental Health Survey Initiative. World Psychiatry. 2007;6:168-76.

3 Kessler RC, Aguilar-Gaxiola S, Alonso J, Chatterji S, Lee S, Ormel J, et al. The global burden of mental disorders: an update from the WHO World Mental Health (WMH) surveys. Epidemiol Psichiatr Soc. 2009;18:23-33.

4 Regier DA, Narrow WE, Clarke DE, Kraemer HC, Kuramoto SJ, Kuhl EA, et al. DSM-5 field trials in the United States and Canada, Part II: test-retest reliability of selected categorical diagnoses. Am J Psychiatry. 2013;170:59-70.

5 Uher R, Rutter M. Basing psychiatric classification on scientific foundation: problems and prospects. Int Rev Psychiatry. 2012;24: 591-605.

6 Smoller JW. Disorders and borders: psychiatric genetics and nosology. Am J Med Genet B Neuropsychiatr Genet. 2013;162B:559-78.

7 Rutter M, Moffitt TE, Caspi A. Gene-environment interplay and psychopathology: multiple varieties but real effects. J Child Psychol Psychiatry. 2006;47:226-61.

8 Paus T. Population neuroscience: why and how. Hum Brain Mapp. 2010;31:891-903.

9 Paus T. Population neuroscience. New York: Springer. 2013.

10 Salum GA, Gadelha A, Pan PM, Moriyama TS, Graeff-Martins AS, Tamanaha AC, et al. High risk cohort study for psychiatric disorders in childhood: rationale, design, methods and preliminary results. Int $\mathrm{J}$ Methods Psychiatr Res. 2015;24:58-73.

11 Pan PM, Sato JR, Salum GA, Rohde LA, Gadelha A, Zugman A, et al. Ventral striatum functional connectivity as a predictor of adolescent depressive disorder in a longitudinal community-based sample. Am J Psychiatry. 2017; 174:1112-9.

12 Mansur RB, Cunha GR, Asevedo E, Zugman A, Rizzo LB, GrassiOliveira R, et al. Association of serum interleukin- 6 with mental health problems in children exposed to perinatal complications and social disadvantage. Psychoneuroendocrinology. 2016;71:94-101.

13 de Araujo CM, Zugman A, Swardfager W, Belangero SIN, Ota VK, Spindola LM, et al. Effects of the brain-derived neurotropic factor variant Val66Met on cortical structure in late childhood and early adolescence. J Psychiatr Res. 2018;98:51-8.

14 Hoexter MQ, Biazoli CE Jr, Alvarenga PG, Batistuzzo MC, Salum GA, Gadelha A, et al. Low frequency fluctuation of brain spontaneous activity and obsessive-compulsive symptoms in a large school-age sample. J Psychiatr Res. 2018;96:224-30.

15 Simioni AR, Pan PM, Gadelha A, Manfro GG, Mari JJ, Miguel EC, et al. Prevalence, clinical correlates and maternal psychopathology of deliberate self-harm in children and early adolescents: results from a large community study. Braz J Psychiatry. 2018;40:48-55.

16 Mansur RB, Cunha GR, Asevedo E, Zugman A, Rios AC, Salum GA, et al. Perinatal complications, lipid peroxidation, and mental health problems in a large community pediatric sample. Eur Child Adolesc Psychiatry. 2017;26:521-9.

17 Sato JR, Biazoli CE Jr, Salum GA, Gadelha A, Crossley N, Satterthwaite TD, et al. Temporal stability of network centrality in control and default mode networks: specific associations with externalizing psychopathology in children and adolescents. Hum Brain Mapp. 2015;36:4926-37.

18 Montagner R, Mogg K, Bradley BP, Pine DS, Czykiel MS, Miguel EC, et al. Attentional bias to threat in children at-risk for emotional disorders: role of gender and type of maternal emotional disorder. Eur Child Adolesc Psychiatry. 2016;25:735-42.

19 Saad LO, do Rosario MC, Cesar RC, Batistuzzo MC, Hoexter MQ, Manfro GG, et al. The child behavior checklist-obsessive-compulsive subscale detects severe psychopathology and behavioral problems among school-aged children. J Child Adolesc Psychopharmacol. 2017;27:342-8.

20 Lima Lde A, Feio-dos-Santos AC, Belangero S, Gadelha A, Bressan RA, Salum GA, et al. An integrative approach to investigate the respective roles of single-nucleotide variants and copy-number variants in Attention-Deficit/Hyperactivity Disorder. Sci Rep. 2016;6:22851.

21 Fatori D, Salum GA, Rohde LA, Pan PM, Bressan R, Evans-Lacko S, et al. Use of mental health services by children with mental disorders in two major cities in Brazil. Psychiatr Serv. 2019;70:337-41.

22 Fatori D, Salum G, Itria A, Pan P, Alvarenga P, Rohde LA, et al. The economic impact of subthreshold and clinical childhood mental disorders. J Ment Health. 2018;27:588-94.

23 Victora CG, Hallal PC, Araújo CL, Menezes AM, Wells JC, Barros FC. Cohort profile: the 1993 Pelotas (Brazil) birth cohort study. Int J Epidemiol. 2008;37:704-9.

24 Gonçalves H, Assunção MC, Wehrmeister FC, Oliveira IO, Barros FC, Victora CG, et al. Cohort profile update: the 1993 Pelotas (Brazil) birth cohort follow-up visits in adolescence. Int J Epidemiol. 2014;43: 1082-8.

25 Anselmi L, Menezes AM, Hallal PC, Wehrmeister F, Gonçalves H, Barros FC, et al. Socioeconomic changes and adolescent psychopathology in a Brazilian birth cohort study. J Adolesc Health. 2012; 51(6 Suppl):S5-10.

26 Anselmi L, Menezes AM, Barros FC, Hallal PC, Araujo CL, Domingues MR, et al. Early determinants of attention and hyperactivity problems in adolescents: the 11-year follow-up of the 1993 Pelotas (Brazil) birth cohort study. Cad Saude Publica. 2010;26:1954-62.

27 Santos IS, Barros AJ, Matijasevich A, Domingues MR, Barros FC, Victora CG. Cohort profile: the 2004 Pelotas (Brazil) birth cohort study. Int J Epidemiol. 2011;40:1461-8.

28 La Maison C, Munhoz TN, Santos IS, Anselmi L, Barros FC, Matijasevich A. Prevalence and risk factors of psychiatric disorders in early adolescence: 2004 Pelotas (Brazil) birth cohort. Soc Psychiatry Psychiatr Epidemiol. 2018;53:685-97.

29 Petresco S, Anselmi L, Santos IS, Barros AJ, Fleitlich-Bilyk B, Barros $\mathrm{FC}$, et al. Prevalence and comorbidity of psychiatric disorders among 
6-year-old children: 2004 Pelotas birth cohort. Soc Psychiatry Psychiatr Epidemiol. 2014;49:975-83.

30 Tovo-Rodrigues L, Schneider BC, Martins-Silva T, Del-Ponte B, Loret de Mola C, Schuler-Faccini L, et al. Is intrauterine exposure to acetaminophen associated with emotional and hyperactivity problems during childhood? Findings from the 2004 Pelotas birth cohort. BMC Psychiatry. 2018;18:368.

31 Schooling CM, Hui LL, Ho LM, Lam TH, Leung GM. Cohort profile: 'children of 1997': a Hong Kong Chinese birth cohort. Int J Epidemiol. 2012;41:611-20.

32 Leung CY, Leung GM, Schooling CM. Behavioral problem trajectories and self-esteem changes in relation with adolescent depressive symptoms: a longitudinal study. Soc Psychiatry Psychiatr Epidemiol. 2018;53:673-84.

33 Wang H, Lin SL, Leung GM, Schooling CM. Age at onset of puberty and adolescent depression: "Children of 1997" birth cohort. Pediatrics. 2016 Jun;137(6). pii: e20153231. doi: 10.1542/peds.2015-3231.

34 Richter L, Norris S, Pettifor J, Yach D, Cameron N. Cohort profile: Mandela's children: the 1990 birth to twenty study in South Africa. Int J Epidemiol. 2007;36:504-11.

35 Verkuijl NE, Richter L, Norris SA, Stein A, Avan B, Ramchandani PG. Postnatal depressive symptoms and child psychological development at 10 years: a prospective study of longitudinal data from the south African birth to twenty cohort. Lancet Psychiatry. 2014;1: 454-60.

36 Raine A, Liu J, Venables PH, Mednick SA, Dalais C. Cohort profile: the Mauritius Child Health Project. Int J Epidemiol. 2010;39:1441-51.

37 Liu J, Raine A, Venables PH, Mednick SA. Malnutrition at age 3 years and externalizing behavior problems at ages 8,11 and 17 years. Am J Psychiatry. 2004:161:2005-13.

38 Liu J, Raine A, Wuerker A, Venables PH, Mednick S. The association of birth complications and externalizing behavior in early adolescents: direct and mediating effects. J Res Adolesc. 2009;19:93-111.

39 Akutagava-Martins GC, Salatino-Oliveira A, Kieling C, Genro JP, Polanczyk GV, Anselmi L, et al. COMT and DAT1genes are associated with hyperactivity and inattention traits in the 1993 Pelotas birth cohort: evidence of sex-specific combined effect. J Psychiatry Neurosci. 2016;41:405-12.

40 Tovo-Rodrigues L, Rohde LA, Menezes AM, Polanczyk GV, Kieling $\mathrm{C}$, Genro JP, et al. DRD4 rare variants in Attention-Deficit/Hyperactivity Disorder (ADHD): further evidence from a birth cohort study. PLoS One. 2013;8:e85164.

41 Kieling C, Hutz MH, Genro JP, Polanczyk GV, Anselmi L, Camey S, et al. Gene-environment interaction in externalizing problems among adolescents: evidence from the Pelotas 1993 birth cohort study. J Child Psychol Psychiatry. 2013;54:298-304.

42 Anselmi L, Fleitlich-Bilyk B, Menezes AM, Araújo CL, Rohde LA. Prevalence of psychiatric disorders in a Brazilian birth cohort of 11-year-olds. Soc Psychiatry Psychiatr Epidemiol. 2010;45:135-42.

43 Anselmi L, Barros FC, Teodoro ML, Piccinini CA, Menezes AM, Araujo $\mathrm{CL}$, et al. Continuity of behavioral and emotional problems from pre-school years to pre-adolescence in a developing country. J Child Psychol Psychiatry. 2008;49:499-507.

44 Gonçalves H, Soares AL, Santos AP, Ribeiro CG, Bierhals IO, Vieira LS, et al. Adverse childhood experiences and consumption of alcohol, tobacco and illicit drugs among adolescents of a Brazilian birth cohort. Cad Saude Publica. 2016;32:e00085815.

45 Silva VL, França GV, Munhoz TN, Santos IS, Barros AJ, Barros FC, et al. Hospitalization in the first years of life and development of psychiatric disorders at age 6 and 11: a birth cohort study in Brazil. Cad Saude Publica. 2018;34:e00064517.

46 Munhoz TN, Santos IS, Barros AJ, Anselmi L, Barros FC, Matijasevich A. Perinatal and postnatal risk factors for disruptive mood dysregulation disorder at age 11: 2004 Pelotas birth cohort study. J Affect Disord. 2017;215:263-8.

47 Murray E, Pearson R, Fernandes M, Santos IS, Barros FC, Victora $\mathrm{CG}$, et al. Are fetal growth impairment and preterm birth causally related to child attention problems and ADHD? Evidence from a comparison between high-income and middle-income cohorts. J Epidemiol Community Health. 2016;70:704-9.

48 Del-Ponte B, Anselmi L, Assunção MC, Tovo-Rodrigues L, Munhoz $\mathrm{TN}$, Matijasevich A, et al. Sugar consumption and attention-deficit/ hyperactivity disorder (ADHD): a birth cohort study. J Affect Disord. 2019;243:290-6.

49 Del-Ponte B, Santos IS, Tovo-Rodrigues L, Anselmi L, Munhoz TN, Matijasevich A. Caffeine consumption during pregnancy and ADHD at the age of 11 years: a birth cohort study. BMJ Open. 2016;6: e012749.

50 Matijasevich A, Murray J, Cooper PJ, Anselmi L, Barros AJ, Barros FC, et al. Trajectories of maternal depression and offspring psychopathology at 6 years: 2004 Pelotas cohort study. J Affect Disord. 2015; $174: 424-31$

51 Santos IS, Matijasevich A, Barros AJ, Barros FC. Antenatal and postnatal maternal mood symptoms and psychiatric disorders in preschool children from the 2004 Pelotas birth cohort. J Affect Disord. 2014;164:112-7.

52 Delgado CA, Munhoz TN, Santos IS, Barros FC, Manitto AM. Prolonged breastfeeding for 24 months or more and mental health at 6 years of age: evidence from the 2004 Pelotas Birth Cohort Study, Brazil. Child Adolesc Ment Health. 2017;22:209-15.

53 Santos IS, Barros FC, Munhoz T, Matijasevich A. Gestational age at birth and behavioral problems from four to 11 years of age: birth cohort study. BMC Pediatr. 2017;17:184.

54 Santos IS, Barros AJ, Barros FC, Munhoz TN, Da Silva BD, Matijasevich A. Mother-child bed-sharing trajectories and psychiatric disorders at the age of 6 years. J Affect Disord. 2017;208:163-9.

55 Leung CY, Leung GM, Schooling CM. Mode of delivery and child and adolescent psychological well-being: evidence from Hong Kong's "Children of 1997" birth cohort. Sci Rep. 2017;7:15673.

56 Leung CY, Leung GM, Schooling CM. Early second-hand smoke exposure and child and adolescent mental health: evidence from Hong Kong's 'Children of 1997' birth cohort. Addiction. 2015;110: 1811-24.

57 Leung CY, Leung GM, Schooling CM. Informal child care and adolescent psychological well-being: Hong Kong's "Children of 1997" birth cohort. PLoS One. 2015;10:e0120116.

58 Wang $\mathrm{H}$, Leung GM, Schooling CM. Life course adiposity and adolescent depressive symptoms among Hong Kong adolescents. J Adolesc Health. 2014;55:408-14.

59 Kwok MK, Leung GM, Schooling CM. Breast feeding and early adolescent behaviour, self-esteem and depression: Hong Kong's 'Children of 1997' birth cohort. Arch Dis Child. 2013;98:887-94.

60 Sabet F, Richter LM, Ramchandani PG, Stein A, Quigley MA, Norris $S A$. Low birthweight and subsequent emotional and behavioural outcomes in 12-year-old children in Soweto, South Africa: findings from birth to twenty. Int J Epidemiol. 2009;38:944-54.

61 Raine A, Venables PH, Mednick SA. Low resting heart rate at age 3 years predisposes to aggression at age 11 years: findings from the Mauritius Joint Child Health Project. J Am Acad Child Adolesc Psychiatry. 1997;36:1457-64.

62 Raine A, Reynolds C, Venables PH, Mednick SA, Farrington DP. Fearlessness, stimulation-seeking, and large body size at age 3 years as early predispositions to childhood aggression at age 11 years. Arch Gen Psychiatry. 1998;55:745-51.

63 Raine A, Yaralian PS, Reynolds C, Venables PH, Mednick SA Spatial but not verbal cognitive deficits at age 3 years in persistently antisocial individuals. Dev Psychopathol. 2002;14:25-44.

64 Venables PH. The Emanuel Miller Memorial Lecture 1987. Childhood markers for adult disorders. J Child Psychology Psychiatry. 1989;30: 347-64.

65 Venables PH. Schizotypy and maternal exposure to influenza and to cold temperature: the Mauritius study. J Abnorm Psychol. 1996;105: 53-60.

66 Axelrud LK, Santoro ML, Pine DS, Talarico F, Gadelha A, Manfro $\mathrm{GG}$, et al. Polygenic risk score for Alzheimer's disease: implications for memory performance and hippocampal volumes in early life. Am J Psychiatry. 2018;175:555-63.

67 Fidalgo TM, Sanchez ZM, Ribeiro M, Healy SR, Caetano SC, Martins SS. A school-based epidemiological field survey: difficulties in collecting psychiatric outcome data in a middle-income country. BMC Psychiatry. 2017;17:277.

68 Kapur S, Phillips AG, Insel TR. Why has it taken so long for biological psychiatry to develop clinical tests and what to do about it? Mol Psychiatry. 2012;17:1174-9. 